\title{
MAKAM LEGENDA ORANG KAYO HITAM: SEBUAH ANALISIS HISTORIS
}

\author{
Mhd Ikhwan \\ Foni Refika Anggela \\ Jurusan Pendidikan Sejarah Universitas Jambi \\ mhdikhwan1209@gmail.com
}

\begin{abstract}
:
This article aims to describe the historical facts found in the legendary tomb of the Orang kayo hitam. The inscription begins with a brief history of Legend of the Orang kayo hitam then followed by the exposure of research results in the Tomb of legend Orang kayo hitam located in the village of Simpang Berbak District Tanjung Jabung Timur. The methods of study used are qualitative methods with data collection techniques in the form of observations, interviews, and documentation. Researchers conducted interviews in-depth with the tombs of the tomb of the Orang kayo hitam and the pilgrims who were dating to make a pilgrimage to the tomb. The results of this study include the history of the Orang kayo hitam, the hereditary lineage of the Orang kayo hitam, the love story of the Orang kayo hitam with the Princess Mayang mangurai, Keris Siginjai and the Orang kayo hitam, the Invisible Kingdom of the Orang kayo hitam, know the tomb of the Orang kayo hitam, Myths and traditions in the tomb of the Orang kayo hitam, the invention of the tomb of the Orang kayo hitam.

Keywords: tomb, legend of the Orang kayo hitam, historical analysis
\end{abstract}

\section{PENDAHULUAN}

Legenda Orang Kayo Hitam hingga saat ini masih banyak diperbincangkan dikalangan masyarakat, dan menjadi salah satu legenda yang terkenal di masyarakat. Dikisahkan memiliki kekuatan yang tidak biasa, Orang Kayo Hitam di anggap sebagai salah satu penguasa jambi yang disegani oleh kerajaan lain pada masa itu. Orang Kayo Hitam adalah anak dari Datuk Paduko Berhalo. Dalam kisah raja-raja Jambi, Orang Kayo Hitamlah yang disebut sebagai pendiri kerajaan/kesultanan Jambi pada abad ke 14-15 Masehi. Kisah keberadaan Orang Kayo Hitam penuh mitos. Salah satunya soal kesaktiannya, serta kisah penaklukan Raja Jambi ini ke Tanah Jawa atau Mataram. Namun, di komplek pemakaman raja ini, sejumlah fakta aneh dapat kita jumpai.

Masih banyak masyarakat yang ingin mengetahui sejarah yang sebenarnya tentang Orang Kayo Hitam. Melalui makam Orang Kayo Hitam yang terletak di Tanjung Jabung Timur banyak fakta yang dapat diketahui, dan dapat menjawab pertanyaan masyarakat tentang kehidupan Orang Kayo Hitam. Bukan hanya kisah tentang Orang Kayo Hitam yang dipenuhi oleh mitos, namun begitu pula dengan makam dari Orang Kayo Hitam. Terdapat beberapa mitos yang di percaya di area pemakaman tersebut, dan tradisi yang hingga saat ini masih dilaksanakan di pemakaman tersebut.

Dengan banyaknya pertanyaan mengenai sejarah dari Orang Kayo Hitam maupun sejarah dari makam Orang Kayo Hitam, kami melakukan penelitan ini 
untuk menjawab rasa penasaran masyarakat tentang cerita sejarah yang sangat dikenal oleh masyarakat. Dengan melakukan metode wawancara, banyak informasi yang telah kami dapatkan mengenai sejarah Orang Kayo Hitam maupun sejarah Orang Kayo Hitam.

Dengan penelitian ini, kami dapat menggali lebih dalam mengenai sejarah Orang Kayo Hitam dan tentang situs makam Orang Kayo Hitam. Dengan dibuatnya makalah ini kami berharap agar, makalah ini dapat dijadikan sebagai sumber dalam mempelajari sejarah tentang Orang Kayo Hitam dan situs makam Orang Kayo Hitam. Penelitian kami ini juga untuk mengangkat tentang wisata sejarah di provinsi jambi, agar lebih dikenal semua orang terutama tentang situs makam orang kayo hitam yang ada di tanjung jabung timur.

\section{METODE PENELITIAN}

\section{Pendekatan dan Jenis Penelitian}

Penelitian kualitatif adalah metode penelitian yang berfokus pada pemahaman terhadap fenomena sosial yang terjadi di masyarakat. Pada metode penelitian ini, peneliti menggunakan perspektif dari partisipan sebagai gambaran yang diutamakan dalam memperoleh hasil penelitian.

Tujuan dari penelitian kualitatif adalah untuk menganalisis yang diteliti agar diperoleh informasi mengenai pelaku mereka, perasaannya, keyakinan ide, bentuk pemikiran, serta dapat menghasilkan sebuah teori. Pendeskripsian data-data dilakukan dengan cara menunjukkan fakta-fakta yang berhubungan atau menjelaskan struktur dan nilai-nilai apa saja yang terdapat dalam legenda Orang Kaayo Hitam.

Penelitian sastra, sebagaimana penelitian disiplin lain, bersandar pada metode yang sistematis. Hanya saja penelitian sastra bersifat deskriptif karena itu metodenya juga digolongkan ke dalam metode deskriptif. Metode deskriptif meripakan prosedur penelitian yang berupaya memecahkan masalah-masalah penelitian dengan cara mengungkapkan dan menggambarkan objek penelitian apa adanya. Penggambaran tersebut berdasarkan pada fakta-fakta yang ada secara objektif.

Dalam penelitian ini kami melakukan penelitian dengan metode penelitian kualitatif, dengan melakukan wawancara langsung ke kompleks perkuburan Orang Kayo Hitam tersebut dengan mewawancarai juru kunci makam tersebut, dan kami juga melakukan wawancara terhadap beberapa peziarah di makam Orang Kayo Hitam.

Karena penelitian ini adalah salah satu jenis penelitian falklor, metode yang digunakan adalah metode etnografi. Metode etnografi relevan dengan penelitian tentang tradisi lisan atau tradisi budaya. Metode etnografi merupakan metode penelitian lapangan yang bersifat holistik-integratif, thick description, dan analisis kualitatif dalam rangka mendapatkan native's point of view.

Selain melakukan wawancara di makam Orang Kayo Hitam, kami juga melakukan wawancara di Museum Rakyat Siginjai untuk menambah referensi dari hasil penelitian kami di Makam Orang Kayo Hitam tersebut. Kami juga menambah referensi dari beberapa jurnal dan beberapa buku. (Sugiyono, 2010) 


\section{Data dan Sumber Penelitian}

Data penelitian ini adalah teks cerita legenda Orang Kayo hitam yang diperoleh melalui informasi lisan dari para narasumber yang kemudian ditranskripsikan ke dalam cerita secara tertulis. Dalam penelitian digali melalui sumber data, yaitu informan dan dokumentasi.

Data yang digali dari informan dan dokumentasi adalah data legenda Orang Kayo Hitam dilapangan. Data dari informan merupakan data primer, sedangkan data dari dokumentasi merupakan data tambahan (sekunder). Data-data utama yang didapatkan dari narasumber kemudian direkam.perekaman dilakukan saat penelitian sedang berlangsung.

Selain data utama tersebut, peneliti juga melengkapi penelitian dengan fotofoto atau gambar-gambar. Penggunaan foto atau gambar tersebut nantinya bukanlah sebagai bahan analisis, tetapi hanya sekedar pelengkap data. Foto atau gambar yang akan ditampilakan adalah foto atau gambar informan, benda-benda lain, atau tempat-tempat yang dianggap berhubungan dengan penelitian.

\section{PEMBAHASAN}

\section{Sejarah Orang Kayo Hitam}

Silsilah turunan Orang Kayo Hitam

Rangkayo Hitam adalah putra Raja Jambi Datuk Paduko Berhalo dengan permaisuri Putri Selaras Pinang Masak. Datuk Paduko Berhalo memiliki nama asli Ahmad Barus atau Ahmad Salim. Datuk Paduko Berhalo diyakini masih keturunan ke tujuh dari cicit Nabi Muhammad SAW, Ali Zainal Abidin bin Husain Bin Ali Bin Abi Thalib RA dari istrinya Fatimah Az Zahra Binti Muhammad SAW.

Dia berasal dari Turki yang datang ke Jambi untuk menyebarkan agama Islam. Sedangkan Putri Selaras Pinang Masak berasal dari Kerajaan Pagaruyung dan merupakan Putri Raja Pagaruyung. Pasangan Datuk Paduko Berhalo dan Putri Selaras Pinang Masak memiliki empat orang anak pertama Rangkayo Pingai alias Sayyid Ibrahim, kedua Rangkayo Hitam Sayyid Ahmad Kamil, ketiga Rangkayo Kedataran Sayyid Abdul Rahman dan terakhir, Rangkayo Gemuk Syarifah Siti Alawiyah. (Tim penulis Kesultanan Jambi Dalam Konteks Sejarah Nusantara, 2011)

\section{Kisah cinta Orang Kayo Hitam dengan Putri Mayang Mangurai}

Suatu masa ketika Rangkayo Hitam telah menginjak dewasa, ia melakukan perjalanan, pengembaraan ke pedalaman negeri Jambi, seperti kebiasaan calon-calon raja tempo dulu. Terdapat banyak pelajaran dalam setiap perjalanan. "Jauh berjalan banyak dilihat, lama hidup banyak dirasa", begitu kata pepatah. Dengan pengembaraan menyusuri setiap sudut negeri ia akan tahu bagaimana kondisi rakyatnya, ia akan banyak belajar tentang kehidupan dan dapat pula berguru ilmu dari orang-orang hebat.

Setelah pamit kepada orang tuanya, Rangkayo Hitam berangkat menyusuri Sungai Batanghari ke hulu dari tempat asalnya di hilir. Sungai Batanghari merupakan sungai terpanjang di pulau sumatera, melewati alam minangkabau hingga negeri Jambi dan bermuara ke samudra. 
Setelah jauh perjalanan berhari-hari sampailah Rangkayo Hitam di percabangan Sungai Batanghari dan Sungai Tembesi. Rangkayo Hitam berhenti sejenak dan memutuskan menyusuri Sungai Tembesi. Dalam dirinya muncul firasat bahwa di sepanjang alur Sungai Tembesi akan ia temukan orang hebat. Perjalanan dilanjutkan, hingga ia kembali menjumpai percabangan sungai, yakni Batang Tembesi dan Sungai Air Hitam, kembali ia beristirahat melepas lelah.

Dalam peristirahatannya itu, tanpa disengaja Rangkayo Hitam melihat perempuan dengan rambut terurai indah di tepi sungai. Terpana lah ia akan kecantikannya, ingin hatinya berkenalan dengan sosok tersebut. Namun belum sempat ia mendekat dan berkenalan, perempuan itu telah berlalu pergi dan menghilang. Walau hanya sebentar ia melihat, namun kejadian itu tidak bisa dilupakan oleh Rangkayo Hitam.Wajah cantik itu selalu terbayang-bayang olehnya sampai terbawa mimpi. Ia kemudian bertekad mencari tahu siapa sosok dengan rambut terurai indah tersebut.

Rangkayo Hitam menapakkan kaki di daratan dan berjalan menjauhi tepi sungai dan bertemu dengan seorang warga. Dari mulut warga itu lah ia tahu bahwa daerah itu adalah Daerah Air Hitam yang dipimpin oleh Pendekar Sakti yang bergelar Datuk Tumenggung Merah Mato. Mendengar kesaktian Datuk Tumenggung itu, ingin hatinya berguru ilmu walau sebentar. Dimintai lah warga agar menunjukkan jalan menuju kediaman Datuk Tumenggung Merah Mato. Takdir berkata lain, sesampainya di tempat Tumenggung ia kembali melihat gadis yang pernah ia lihat tempo hari. Tahulah Rangkayo Hitam bahwa gadis yang ia lihat itu bernama Mayang Mangurai anak Tumenggung Merah Mato. Niat hati ingin berguru menjadi berubah ingin melamar anak Tumenggung Merah Mato.

Tentu saja melamar anak seorang pendekar nan sakti itu tidak mudah. Tumenggung Merah Mato pun tidak begitu saja mau melepaskan anak gadisnya ke tangan seorang laki-laki yang baru ia kenal, walaupun kemudian ia tahu bahwa di depannya adalah raja Jambi di masa mendatang, anak Datuk Paduko Berhalo di Tanjung Jabung. Ia harus tetap diuji, seberapa layak pemuda di hadapannya untuk menjadi suami anak kesayangannya. Telah banyak pria yang ingin melamar, namun gagal karena tidak mampu memenuhi syarat yang diajukan Tumenggung Merah Mato.

Tindakan Tumenggung Merah Mato yang demikian protektifnya bolehboleh saja dipuji sebagai bentuk cinta ayah kepada anaknya. Ia jaga kehormatan anak perempuannya dan tak akan ia lepaskan kepada sembarang laki-laki. Namun jika terus begini boleh jadi sulit bagi Mayang Mangurai mendapatkan jodoh. Mayang Mangurai memang cantik jelita,telah banyak laki-laki datang ke rumahuntuk melamar, baik dari orang bisa,pendekar hingga bangsawan kayaraya,dari pemuda yang tak iakenal hinggapemuda yang ia kenal. Mayang Mangurai terkadang sedih karena di usianya yang sudah pantas untuk menikah itu belum satupun pelamardapat memenuhi syarat yang diajukan oleh Tumenggung Merah Mato. Sebagai pendekar, dan berkecimpung di dunia persilatan, tentu tolak ukur kehebatan bagi Tumenggung Merah Mato adalah ilmu "kanuragan" atau beladiri, berbeda dengan zaman sekarang yang tolak ukurnya mungkin hal-hal lain seperti harta, pendidikan atau gelar akademik. Rangkayo Hitam pun diberlakukan 
sama dengan pelamar lain, ilmu bela diri dankesaktiannya diuji oleh Tumenggung Merah Mato.

Rangkayo Hitam harus berhadapan dengan pengawal pribadi Tumenggung Merah Mato. Pengawal itu bukanlah orang sembarangan, ilmu beladiri dan kesaktiannya luar biasa. Selama ini hanya Tumenggung Merah Mato yang mampu menandinginya. Walau Rangkayo Hitam sejak kecil sudah dididik ilmu beladiri, sebagai ilmu wajib calon raja, ujian itu belum tentu dapat ia lewati.

Gelanggang pun dipersiapkan, berdo'alah Rangkayo Hitam kepada Tuhan agar dimenangkan dirinya dalam pertarungan itu. Pengawal pribadi Tumenggung Merah Mato telah berdiri dan tak sabar menguji lawan tandingnya itu. Telah lama ia tidak menemukan lawan tanding yang sepadan.

Tak begitu lama, pertarungan dua pendekar pun dimulai. Penduduk Negeri Air Hitam pun ikut menyaksikan kehebatan dua pendekar tersebut. Tiga hari tiga malam lamanya, pertarungan itu berlangsung, berhenti hanya waktu shalat dan makan. Sampai dua hari belum ada yang terlihat kalah-mengalah, semua jurus dan segala jenis senjata dipergunakan, keduanya masih terlihat seimbang. Pada hari ketiga barulah pengawal itu kewalahan dan mengakui keunggulan Rangkayo Hitam.

Putri Mayang Mangurai yang sejak beberapa hari ini mendengar kabar kedatangan pemuda yang ingin melamar dirinya, sebetulnya sudah jatuh hati pula kepada Rangkayo Hitam, apalagi setelah mendengar kabar pemuda gagah itu orang baik-baik dari keturunan yang baik dan terpandang pula, anak Paduko Berhalo di Tanjung Jabung. Pemuda gagah itu mampu menaklukkan pengawal pribadi ayahandanya yang selama ini selalu menjadi tembok penghalang dirinya untuk dapat menikahi pria yang ia cintai. Ia merasa inilah jawaban Tuhan atas do'a-do'anya selama ini.

Setelah pertarungan itu selesai, Tumenggung Merah Mato masih mengajukan syarat yang harus dipenuhi Rangkayo Hitam dalam waktu paling lama 6 bulan; yaitu emas selesung pesuk, seruas buluh talang dan selengan baju, segantang kepala tungau ulang alik (bahasa kiasan). Maknanya, Rangkayo Hitam harus menyiapkan harta sebanyak yang ia minta jika ingin melamar Mayang Mangurai. Berat memang melamar anak pendekar hebat dan terpandang, namun Rangkayo Hitam tidak menyerah begitu saja. Sekali layar terkembang, pantang surut ke belakang, Rupanya ia sudah jatuh cinta betul kepada Mayang Mangurai. Ia pamit pulang untuk memenuhi syarat yang diajukan Tumenggung Merah Mato. Mayang Mangurai sedih mendengar syarat ayahandanya yang keterlaluan dan hampir mustahil dipenuhi. Tim Penulis, Kesultanan Jambi Dalam Konteks Sejarah Nusantara, 2011)

Ke pulau jawa Rangkayo Hitam mencari relasi untuk dapat memenuhi syarat yang diajukan Tumenggung Merah Mato. Ia temui bangsawan-bangsawan jawa yang dapat dimintai bantuan. Untunglah Rangkayo Hitam anak seorang Raja Jambi yang dikenal baik oleh bangsawan negeri seberang. Terbantulah kesulitan Rangkayo Hitam oleh para bangsawan itu tidak sampai enam bulan.

Syarat yang dicari sudah terpenuhi, Rangkayo Hitam pulang ke Negeri Jambi. Sesampainya di Jambi bersama dengan keluarga besar ia melamar Mayang Mangurai. Pernikahan akbar pun berlangsung dan pesta digelar berhari-hari. 
Sebagai tanda memulai bahtera kehidupan yang baru, kedua pasangan ini dihadiahi perahu Kajang Lako dan sepasang angsa. Angsa ini akan menjadi petunjuk bagi kedua pasangan ini dimana wilayah yang tepat untuk berhenti dan membangun pemukiman baru. Menggunakan perahu itu Rangkayo Hitam kedua pasangan ini mencari wilayah baru yang untuk memulai biduk rumah tangga baru. Akhirnya sampai lah mereka di suatu wilayah yang kemudian hari menjadi wilayah Istana Tanah Pilih (Jambi) dan pusat kerajaan Jambi (Kota Jambi sekarang). Kisah Rangkayo Hitam mempersunting Putri Mayang Mengurai masih melegenda di tengah-tengah Masyarakat Jambi (dengan berbagai versi). (Kurnia, 2013)

\section{Keris siginjai dan Orang Kayo Hitam}

Rangkayo Hitam merupakan seorang Raja Melayu Jambi yang sangat pemberani dan sakti, saat pemerintahan kerajaan dibawah kepemimpinan kakaknya Rangkayo Pingai, Rangkayo Hitam pernah mencegat upeti yang dikirimkan kakaknya kepada kerajaan Mataram yang waktu itu Kerajaan Melayu Jambi merupakan daerah jajahan kerajaan Mataram. Upeti itu berhasil digagalkan oleh Rangkayo Hitam, karena beliau berpendapat bahwa Kerajaan Melayu Jambi merupakan Kerajaan yang berdaulat dan tidak tunduk kepada Kerajaan manapun.

Pada saat itu ancaman terbesar kedaulatan Kerajaan atau Kesultanan Jambi adalah Kerajaan Malaka yang sedang berada di Puncak Kejayaan yang siap merebut kembali wilayah pesisir utara Jambi. Sebagai upaya membendung kekuatan Malaka, maka Jambi memilih untuk tetap tunduk dibawah Kerajaan Majapahit, walaupun tidak sedigjaya dulu lagi ketika masih dipimpin Hayam Wuruk. Konsekuensinya adalah Jambi harus terus mengirimkan upeti ke Majapahit.

Sehingga Kesultanan Jambi selalu mengirimkan upeti ke Jawa. Ketika Rangkayo Hitam mulai dewasa, dia menentang penyerahan upeti tersebut. Sebagai salah satu pewaris tahta kesultanan Jambi. Dia berpendapat sudah selayaknya Jambi menjadi negeri berdaulat dan tidak harus bersusah payah mengirimkan kekayaan kerajaannya ke kerajaan lain. Ketika Datuk Berhalo wafat, pucuk pimpinan Kesultanan Jambi lalu diteruskan oleh Rangkayo Pinggai sebagai putra tertua. Saat pemerintahan kerajaan dibawah kepemimpinan kakaknya Rangkayo Pingai, Rangkayo Hitam pernah mencegat dan menggagalkan upeti yang hendak dikirimkan kakaknya kepada raja Jawa yang memerintah waktu itu. Karena dia berpendapat bahwa Kerajaan Jambi merupakan kerajaan yang berdaulat dan tidak tunduk kepada kerajaan manapun.

Mendengar adanya gejolak di Kerajaan Melayu Jambi yang tidak mau mengirimkan upeti ke Kerajaan Mataram dan tentang adanya seorang sakti bernama Rangkayo Hitam yang menggegalkan Upeti tersebut, maka Raja Mataram merencanakan akan melakukan penyerangan ke kerajaan Melayu yang disebut serangan Pamalayu dan segera memerintahkan seorang empu untuk membuat sebuah keris sakti yang akan digunakan untuk membunuh Rangkayo Hitam.

Mendengar hal tersebut, Rangkayo Hitam berangkat menuju Kerajaan Mataram untuk menggagalkan rencana tersebut. Di daerah mataram Rangkayo 
Hitam bertemu dengan seorang empu yang sedang membuat keris. Rangkayo Hitam bertanya kepada empu untuk siapa keris tersebut, empu itupun menjelaskan bahwa keris tersebut untuk Raja Mataram yang katanya akan digunakan untuk membunuh seorang sakti di Kerajaan Melayu Jambi yang bernama Rangkayo Hitam, saat itu empu juga menjelaskan bahwa keris tersebut dibuat dari tujuh macam besi yang diawali oleh huruf $\mathrm{P}$, dan akan sempurna bila telah dimandikan di tujuh muara.

Rangkayo Hitam pun saat itu juga merebut keris tersebut dari tangan sang empu, dan mengatakan bahwa dialah Rangkayo Hitam. Empu itupun akhirnya tewas di tangan Rangkayo Hitam. Setelah mendapatkan keris, Rangkayo Hitam segera kembali ke Kerajaan Melayu untuk menyiapkan segala sesuatu jika nanti kerajaan Mataram jadi menyerang dan segera ia menyempurnakan keris tersebut di tujuh muara.. Hingga keris tersebut menjadi senjata sakti bagi Rangkayo Hitam.

Rangkayo Hitam sering meletakkan keris tersebut di sanggul rambutnya sehingga orang-orang sering menyebutnya dengan sebutan "Ginjai" yang berarti tusuk konde. Sampai akhirnya keris tersebut diberi nama Keris Siginjai. (Kurnia, 2013)

\section{Kerajaan gaib Orang Kayo Hitam}

Kerajaan gaib ini adalah kerajaan yang dimiliki oleh seorang manusia sakti yang bernama Orang Kayo Hitam. Orang Kayo Hitam adalah salah satu anak Orang Kayo Pingai, raja dari Kerajaan Jambi. Orang Kayo Hitam dikenal sangat sakti, sebuah kisah menceritakan dahulu Kerajaan Jambi selalu mengirim Upeti kepada Kerajaan Mataram di Jawa, namun kebiasaan tersebut kemudian di tentang oleh Orang Kayo Hitam. Pembangkangan tersebut membuat kerajaan Mataram berang sekaligus bimbang karena Orang Kayo Hitam dikenal sangat sakti dan memiliki pasukan gaib. Dengan bantuan peramal kerajaan dari Pemalang titik kelemahan Orang Kayo Hitam ditemukan, ia hanya bisa terbunuh oleh sebilah keris yang logamnya terbuat dari langit dan di sepuh oleh air sungai yang nama sungainya di awali dengan huruf "P". Penempahanya pun harus hanya boleh dilakukan pada setiap hari Jumat yang telah melewat 40 kali Jumat.

Namun upaya untuk membunuh Orang Kayo Hitam tidak juga berhasil karena sebelum keris berhasil dibuat, Orang Kayo Hitam berangkat sendirian menggunakan rakit ke tanah Jawa untuk menghancurkan keris tersebut beserta kerajaan Pemalang itu sendiri. Pada pertempuran tersebut Orang Kayo Hitam menang besar karena dipercaya dibantu oleh pasukan Jin yang jumlahnya 7 kali lipat dibandingkan jumlah pasukan Mataram. Sadar tak bisa dibunuh akhirnya kerajaan Mataram memilih jalan damai dan menawarkan Orang Kayo Hitam menjadi raja di salah satu kerajaan yang berada di bawah kekuasaan Raja Mataram. Namun Orang Kayo Hitam menolak dan memilih kembali ke kampung halamannya dan menjadi raja menggantikan ayahnya. Pada saat menjabat, kerajaannya berkembang besar sehingga kerajaannya tak mampu menampung lagi rakyat yang semakin banyak. Akhirnya dengan kesaktiannya, ia menghancurkan sebuah bukit batu hingga terpecah menjadi sembilan bagian. Orang Kayo Hitam pun memerintahkan rakyatnya untuk mendirikan kerajaan-kerajaan kecil di lokasi 
tempat batu-batu tersebut jatuh. Namun kerajaan-kerajaan kecil tersebut tidak dipimpin oleh raja, melainkan oleh seorang Rio.

Sebelum meninggal dunia, Orang Kayo Hitam memerintahkan pasukan gaibnya untuk menjaga kesembilan kerajaan yang ia bentuk dari segala macam serangan, bencana alam dan sebagainya. Kini pasukan gaib milik Orang Kayo Hitam tersebut dipercaya memiliki kerajaan di Gunung Kerinci, gunung tertinggi di Indonesia yang terdapat di kabupaten Kerinci. Salah satu lokasi yang kerap terjadi penampakan adalah danau kerinci, disana kerap ditemui prajurit setinggi pohon kelapa tengah berbaris. (Usman, 2006)

\section{Makam Orang Kayo Hitam}

\section{Mengenal makam Orang Kayo Hitam}

Makam Rangkayo Hitam terletak di Desa Simpang,Kecamatan Berbak,Kabupaten Tanjung Jabung Timur,dengan panjang 4,8 meter .Makam ini kerap didatangi ratusan peziarah dari berbagai daerah di nusantara.Badan Pelestarian Cagar Budaya (BPCB) Jambi mencatat,bahwa di komplek makam Orang Kayo Hitam terdapat beberapa peninggalan cagar budaya yang berasal dari dua masa yang berbeda (multi component sites).

Rang kayo hitam merupakan anak dari datuk paduka berhala, mempunyai istri yang bernama puteri selaras pinang masak ,makamnya terletak di daerah kumpeh, mereka mempunyai 4 orang anak yaitu rang kayo pingai, rang kayo hitam, rang kayo pedataran, rang kayo gemuk. Datuk paduko berhalo merupakan keturunan dari turki dan puteri selaras pinang masak merupakan keturunan dari kerajaan pagaruyung.

Di situs tersebut terdapat makam rang kayo hitam, makam istri rang kayo hitam (putri mayang mangurai) merupakan putri dari datuk tumenggung merah mato dari air hitam mentawa air raja uluan tembesi, merangin yang merupakan mertua dari rang kayo hitam tersebut. Disitus tersebut juga terdapat makam kucing kesayangan dari rang kayo hitam tersebut, dan makam dari juru kunci yang dahulu kala menjaga makam rang kayo hitam pertama kali yang bernama datuk daur, dan makam putri julan yang merupakan pengikut dari rang kayo hitam, makam putri julan tersebut terdapat di luar area perkuburan rang kayo hitam, tepatnya bersebelahan dengan candi rang kayo hitam yang terletak di luar makam.

Sedangkan candi yang terdapat di area pemakaman tersebut jauh sebelum adanya makan dari rang kayo hitam tersebut yaitu pada zaman hindu-budha. Candi tersebut sezaman dengan candi muaro jambi.

Rang kayo hitam meninggal sekitar tahun 1500 an. Makam dari keturunan datuk paduko berhalo dapat terpisah-pisah karena pada masa pemerintahannya, beliau membagi daerah kekuasaan dari seberang hingga ke tungkal babu (rang kayo pingai), (rang kayo hitam) jari tanjung jabung sampai ujung jabung. Keturunan rang kayo pingai sebagai menteri-menteri kerajaan jambi, sedangkan keturunan dari rang kayo hitam sebagai raja dari kerajaan jambi, keturunan dari rang kayo panataran sebagai panglima-panglima kerajaan. Pusat kerajaan jambi belum diketahui, karena belum ada data yang akurat. (Komunikasi Pribadi, 2019) 


\section{Mitos dan Tradisi di Makam Orang Kayo Hitam}

Larangan di area pemakaman antara lain, saat wanita sedang haid atau menstruasi dilarang untuk masuk ke dalam makam tersebut, karena makam tersebut merupakan tempat yang suci, sehingga wanita yang dalam keadaan kotor tidak diperbolehkan untuk memasuki makam tersebut.

Di area pemakaman sering didatangi oleh para peziarah yang berasal dari berbagai macam suku yang memiliki adat yang berbeda-beda. Para peziarahpun berasal dari berbagai macam agama, karena di area pemakaman tersebut menerima peziarah dari agama manapun. Kebanyakan peziarah membawa berbagai macam makanan ataupun barang-barang saat berziarah, kebanyakan dari mereka pergi berziarah ke makam karena nazar yang mereka inginkan telah terpenuhi.

Makam rang kayo hitam mulanya tidak ditutupi kain putih namun karena mulai munculnya kebiasaan dan pandangan bahwa biasanya makam raja-raja itu tertutup, maka akhirnya makam dari rang kayo hitam tersebut mulai ditutupi dengan kain putih yang dibawa oleh peziarah.(Komunikasi pribdi, 2019)

\section{Penemuan makam Orang Kayo Hitam}

Makam rang kayo hitam ditemukan sudah dari ratusan tahun lalu, dengan panjang ratusan meter, dikarena kan erosi terjadi pengikisan, dan makam tersebut pun awalnya ditemukan didalam hutan. Batu nisan dari makam yang miring juga memiliki cerita tersendiri, yaitu pada zaman VOC, mereka tidak percaya akan kramat rang kayo hitam, mereka menarik batu nisan tersebut menggunakan kapal, namun bukan malah tertarik mengikuti arah kapal tapi malah kebalikan dari arah tersebut, hingga sampai saat ini batu nisan makam rang kayo hitam semuanya miring tidak lurus seperti nisan kebanyakan. Batu nisan yang terdapat pada makam tersebut merupakan batu yang hanya ada di aceh dan di jambi. Batu prasarti yang terdapat di depan area pemakaman merupakan batu prasasti yang di bawa dari sabak saat peresmian dari pemakaman rang kayo hitam tersebut.

Di kompleks perkuburan ini terdapat 4 buah makam, yakni, makam Orang Kayo Hitam, istrinya (Puteri Mayang Mangurai), dan Makam kucing peliharaan Orang Kayo Hitam dan satu lagi adalah makam dari juru kunci situs kramat Orang Kayo Hitam yang bernama Datuk Daur.

Saat pemugaran makam rang kayo hitam juga ditemukan patung kepala singa, tangan arca, keramik-keramik, guci. Kebanyakan peziarah kebanyakan bernazar tentang makam rang kayo hitam karena orang-orang terdahulu dianggap suci dan doanya dikabulkan oleh Allah SWT. Makam rang kayo hitam tetap masuk kedalam wilayah jambi, karena tanah tersebut merupakan tanah jambi. Makam rang kayo hitam di renovasi sekitar tahun 2006/2007.

Pertama adalah Makam Orang Kayo Hitam dan makam Puteri Mayang Mangurai yang merupakan tokoh penting pada masa Kesultanan Jambi yang merepresentasikan masa Islam. Kedua masa Hindu Budha yang dibuktikan dengan adanya tinggalan struktur bata kuno yang diduga sebagai Candi Budha, dugaan ini diperkuat dengan ditemukannya temuan pendukung yang antara lain berupa tangan arca dan arca kepala berwujud singa.. 
Makam Orang Kayo Hitam berbentuk persegi panjang berukuran 5,2 meter x 1,5 meter. Sedangkan makam Puteri Mayang Mangurai berukuran 3,7 meter x 1,4 meter.Ukuran dua makam itu terbilang besar untuk makam manusia kini yang umumnya hanya memiliki panjang 1,5 sampai 2 meter saja.Yang mengejutkan, makam kucing peliharaan Datuk Orang Kayo Hitam juga panjang dan besar, berukuran 3,2 meter x 1,2 meter.

Pada hari-hari tertentu, kita dapat menjumpai para peziarah datang ke pemakaman itu. Selain berdoa, ternyata banyak peziarah yang juga memintaminta sesuatu di makam itu, termasuk memanjatkan niat dan bernazar untuk halhal tertentu.(Komunikasi Pribadi, 2019)

\section{KESIMPULAN}

Penelitian ini dilakukan dengan tujuan mengetahui struktur dan nilainilai budaya yang terdapat di dalam legenda Orang Kayo Hitam. Selain itu, penelitian ini juga dilakukan untuk mengetahui bentuk alternatif bahan ajar seperti apa yang dapat disusun dari legenda Orang Kayo Hitam guna diterapkan dalam proses pembelajaran.

Dalam penelitian ini, penulis menggunakan metode etnografi dan analisis truktural. Dari hasil penelitian diketahui bahwa legenda Orang Kayo Hitam terdiri dari dua bagian besar, yaitu sejarah Orang Kayo Hitam dan Makam Orang Kayo Hitam.

Kedua penggalan cerita Orang Kayo Hitam tersebut saling berkaitan dan dapat diurutkan sesuai dengan urutan kronologis kejadian dalam kehidupan Orang Kayo Hitam. Penggalan cerita dilakukan karena alasan panjangnya cerita dan penyesuaian dengan kondisi dan tujuan penceritaan.

Kami menyadari bahwa dalam proses penulisan makalah ini masih jauh dari kesempurnaan, baik materi maupun cara penulisannya. Namun demikian, penulis telah berupaya dengan segala kemampuan dan pengetahuan yang dimiliki sehingga dapat selesai dengan baik. Dan oleh karenanya, penulis dengan rendah hati dan dengan tangan terbuka menerima masukan, saran dan usul guna penyempurnaan makalah ini

\section{DAFTAR PUSTAKA}

Harun, M. Yahya. Kerajaan Islam Nusantara Abad XVI dan XVII. Yogyakarta: PT.

Sejahtera, Kurnia Kalam \&Lindayanti, dkk., (2013), Jambi Dalam Sejarah 15001942, Jambi: Dinas Kebudayaan dan Pariwisata Provinsi Jambi

Tim Penulis. (2011). Kesultanan Jambi Dalam Konteks Sejarah Nusantara, Jakarta: Puslitbang Lektur dan Khazanah Keagamaan Badan Litbang dan Diklat Kementerian Agama RI.

Hasil wawancara dengan juru kunci makam Orang Kayo Hitam bapak M.Mail Iskandar.

Marmoah, Sri. Manajemen Pemberdayaan Perempuan Rimba, Yogyakarta : C.V Budi Utama. 
Mhd Ikhwan, Foni Refika Anggela; Makam Legenda Orang Kayo Hitam: Sebuah Analisis Historis

Sari, Ngebi Sutho Dilogo Priyai Rajo. (1982). Undang-Undang, Piagam, dan Kisah Negeri Jambi, Departemen Pendidikan dan Kebudayaan.

Meng, Usman. (2006). Napak Tilas Liku-liku Provinsi Jambi.

Sugiyono.(2010). Memahami Penelitian Kualitatif. Bandung : Alfabeta.

Wahyudi (2019). Naskah Muqaddimah Al-Mubtadin, (Jakarta: Perpustakaan Nasional Republik Indonesia. 